\title{
A arte de si: uma nova ética do corpo
}

\author{
El arte de sí: una nueva ética del cuerpo
}

The art of self: a new ethics of the body

\section{Cesar Marcos Casaroto Filho ${ }^{1}$}

\begin{abstract}
Resumo
Por meio do estabelecimento de um diálogo entre as ideias de "estética da existência", de Michel Foucault, e de dândi, na esteira de Charles Baudelaire, Daniel Salvatore Schiffer e Michel Onfray, viso pensar o sujeito moderno enquanto artista de si mesmo. Tal sujeito não é constituído substancialmente por alguma entidade perfeita; a subjetividade dândi ocorre na imanência. Ao problematizar as forças socioculturais que interditam a livre expressão do desejo, proponho-me a refletir acerca de um sujeito constituído pelo trabalho estético que faz de si. Em tal concepção, sujeito é forma, ficção, trabalho ético sobre as forças passivas e ativas que o atravessam. Tendo em vista o entendimento de que o sujeito se dá na prática de si, intenciono questionar a ideia de obra de arte enquanto produto cindido da potência vital que a origina. Sendo assim, servindo-me da filosofia de Giorgio Agamben, pretendo pensar o artista de si enquanto força inoperante que resiste aos dispositivos culturais. Dândi é o sujeito que, ciente das suas potencialidades, pelo jogo que faz do seu corpo, no tempo do devir, cria novas formas de vida. $\mathrm{O}$ dandismo é um vitalismo. Dândi é a obra inoperante, inacabada, processo sem outro fim que o de viver para si mesmo, não em prol de forças externas que subjugam suas potencialidades.
\end{abstract}

Palavras-chave: estética; ética; sujeito; dandismo; forma-de-vida.

\section{Resumen}

Por medio del establecimiento de un diálogo entre las ideas de "estética de la existencia", de Michel Foucault, y de dândi, segundo Charles Baudelaire, Daniel Salvatore Schiffer y Michel Onfray, intenciono pensar el sujeto moderno como artista de sí mismo. Tal sujeto no está constituido sustancialmente por alguna entidad perfecta; la subjetividad dandi ocurre en la inmanencia. Al problematizar las fuerzas socioculturales que interdictan la libre expresión del deseo, me propongo reflexionar acerca de un sujeto constituido por el trabajo estético que hace de sí. En esta concepción, sujeto es forma, ficción, trabajo ético sobre las fuerzas pasivas y activas que lo atravesan. Con el entendimiento de que el sujeto sucede en la práctica de sí, intento cuestionar la idea de obra de arte como producto escindido de la potencia vital que la origina. Siendo así, sirviéndome de la filosofía de Giorgio Agamben, pretendo pensar al artista de sí mismo como fuerza inoperante que resiste a los dispositivos culturales. Dandi es el sujeto que, consciente de sus potencialidades, por el juego que hace de su cuerpo, en el tiempo del devenir, crea nuevas formas de vida. El dandismo es un vitalismo. Dandi es la obra inoperante, inacabada, proceso sin otro fin que el de vivir para sí mismo, no en favor de fuerzas externas que subyugan sus potencialidades.

Palabras claves: la estética; la ética; sujeto; dandismo; forma-de-vida.

\begin{abstract}
Through the establishment of a dialogue between the ideas of Michel Foucault's "aesthetics of existence" and dandy, according to Charles Baudelaire, Daniel Salvatore Schiffer and Michel Onfray, the aim is to think of the

\footnotetext{
${ }^{1}$ Doutorando em Teoria da Literatura na área de Letras pela Pontifícia Universidade Católica do Rio Grande do Sul; Porto Alegre; RS; Brasil; cesarcasarotofilho@ gmail.com
} 
modern subject as an artist of himself. This subject is not substantially constituted of a perfect entity; Dandy subjectivity takes place in immanence. In problematizing the sociocultural forces that interdict the free expression of desire, I propose to reflect on a subject constituted by the aesthetic work that makes of itself. In such a conception, subject is form, fiction, ethical work on the passive and active forces that cross it. In view of the understanding that the subject is in the practice of self, I intend to question the idea of a work of art as a product of the vital power that originates it. Thus, using the philosophy of Giorgio Agamben, I intend to think of the artist as a dead force that resists cultural devices. Dandi is the subject who, aware of his potentialities, by the game that he makes of his body, in the time of becoming, creates new forms of life. Dandyism is a vitalism. Dandy is the inoperative, unfinished work, process with no end other than that of living for itself, not for the sake of external forces that subjugate its potentialities.

Keywords: aesthetics; ethic; subject; dandyism; shape-of-life.

\section{Introdução}

Em História da sexualidade: o uso dos prazeres (2017), o filósofo Michel Foucault pensa aquilo que denomina "estética da existência" no contexto social da Grécia clássica. Trata-se de uma prática moral relacionada às formas de subjetivação de cada sujeito "livre". Lembremos que sujeito livre, na Grécia clássica, é o cidadão grego: sujeito masculino não escravo. Na concepção de Foucault, o cristianismo enfraquecerá as "artes da existência" desenvolvidas por aquela sociedade. As ferramentas cristianizadoras implicaram por muitos séculos da nossa hera nas subjetividades de maneira a moldarem aquilo que se compreendeu por indivíduo - atado a valores estéticos voltados para a castidade, a renúncia dos prazeres; de um modo geral, a renúncia de si. A subjetividade da sociedade ocidental traz a marca do mal sexual, do pecado. Uma forma maniqueísta de pensamento - a luta do bem contra o mal influenciou o modo como o sujeito moderno se reconhece como tal. A crença na salvação, por meio da purificação dos pecados - diretamente vinculados às forças sexuais que nos movem -, foi o que regeu por muito tempo o pensamento e os corpos. O processo hermenêutico de que a igreja se utilizou para perscrutar a psique humana imprime até hoje todo um regramento de conduta que cinde corpo e alma, de maneira a punir moralmente o sujeito que procura por novas vias éticas para dar vazão ao seu desejo. Sabemos hoje que a subjetividade não pode ser apreendida no interior de uma estrutura moralizadora, afinal de contas, as formas de vida vão muito além de uma visão unilateral de um certo e de um errado, de um bem e de um mal.

\section{O corpo para a Grécia clássica e o cristianismo}

Na Grécia clássica, as "artes da existência” (Foucault denomina também "tecnologias de si”) são, conforme o filósofo francês,

[...] práticas refletidas e voluntárias através das quais os homens não somente se fixam regras de conduta, como também procuram se transformar, modificar-se em 
seu ser singular e fazer de sua vida uma obra que seja portadora de certos valores estéticos e responda a certos critérios de estilo. (2017, p. 16).

Pensar o sujeito aqui é pensá-lo em sua relação com o social, por meio da sua conduta consigo mesmo e com os outros. O que está em jogo é o trabalho ético do sujeito sobre si mesmo: “[...] não somente para tornar seu próprio comportamento conforme a uma regra dada, mas também para tentar transformar a si mesmo em sujeito moral de sua própria conduta." (FOUCAULT, 2017, p. 34). Trata-se de uma relação de si consigo mesmo, um processo terapêutico necessário para a arte de si. Segundo Foucault, "para ser dita 'moral' uma ação não deve se reduzir a um ato ou a uma série de atos conformes a uma regra, lei ou valor." (2017, p. 36). Assim, uma ação moral implica tanto um código a que se refere quanto uma relação consigo mesmo. O sujeito moral, assim, "estabelece para si um certo modo de ser que valerá como realização moral dele mesmo [...]" (FOUCAULT, 2017, p. 36). Para que isso seja possível, o sujeito deve procurar pôr-se à prova, aperfeiçoar-se, transformar-se, conhecerse na prática de si. Desse modo, conforme Foucault (2017), em seu sentido amplo moral comporta dois aspectos: o dos códigos de comportamento e o das formas de subjetivação. As leis comuns na Grécia clássica permitiam maior liberdade ao indivíduo político de experimentar o próprio corpo. Ao contrário do cristianismo, na Grécia antiga o pensamento prático apresentava maior força devido às leis comuns não ditarem a Lei do texto escrito. A partir desse fato, Foucault (2017) chega à conclusão de que, não havendo necessidade do texto para a manutenção da lei, para os gregos a ética é feita por meio da "téckné", da "prática", do "savoir-faire". Dessa forma, não se trata de universalizar as regras das ações para que o sujeito se torne ético, já que o sujeito ético se constitui "por meio de uma atitude e de uma procura que individualizam sua ação, que modulam e que até podem dar um brilho singular pela estrutura racional e refletida que lhe confere.” (FOUCAULT, 2017, p. 75). Foucault (2017) explica que a reflexão moral, na Antiguidade clássica, não está orientada, como na nossa, para uma "hermenêutica do sujeito", mas para uma "estilização da atitude", uma "estética da existência".

Diferentemente do cristianismo, na Grécia clássica o ato sexual não é regrado por um discurso moralizante que o compreende sob o jugo do Mal. Para os helenos, o ato sexual incomoda unicamente como ameaça ao indivíduo com relação a si mesmo e a própria constituição enquanto sujeito moral. É necessário aqui valorizar a vida por meio da estilização de si. Um regramento a ser seguido enquanto verdade universal está fora de cogitação. Nesse contexto, o corpo não é desprezado por função da marca do Mal original. Daí a estética de si mesmo, o pensar a si mesmo, a experimentação de si, serem menos moralizantes. Ao 
contrário de uma lei universal a ser seguida, a austeridade necessária ao sujeito grego - que é senhor de si mesmo - implica, nas palavras de Foucault, "um princípio de estilização da conduta para aqueles que querem dar à sua existência a forma mais bela e mais realizada possível.” (2017, p. 307). Com o cristianismo, o pensamento acerca da conduta moral não se preocupará mais com o prazer e a estética do seu uso, mas com um desejo marcado pela culpa do pecado.

\section{O trabalho estético/ético de si consigo mesmo}

Como bem explica Cláudio Ulpiano ${ }^{2}$, diferentemente da modernidade, para os gregos a "estética da existência" implica uma compreensão de obra de arte não como produto, mas enquanto obra de si mesmo. $\mathrm{O}$ conceito de arte aqui deve abranger a vida como um todo. Trata-se de uma conduta ética frente à vida. Na "prática de si", a causa da existência deve vir de dentro de si. É algo imanente. Para Ulpiano, a prática de si, operada pela liberdade de pensamento própria do sujeito que tem poder sobre si mesmo, dá-se naquilo que Foucault chama "relação agonística de si consigo próprio", um confronto agonístico que ocorre dentro de si. Para que tal confronto aconteça, o sujeito deve realizar a si mesmo tal qual um "campo de batalha". O indivíduo tornado campo de batalha deve fazer com que as forças ativas dominem as que tendem para a submissão. A vontade de potência é evidente. Para Nietzsche (2016), os "escravos" constituem-se das forças que vêm de fora, não das que podem ser produzidas por eles mesmos. Trata-se da fabricação de novos modos de vida. O que está em jogo aqui é uma força ativa afirmadora da vida e operada na diferença.

Não se trata, como muitos afirmam, de algo desarticulado do social, afinal de contas, é ético o trabalho do artista de si. É com os românticos que uma nova política, uma nova ética/estética do indivíduo começa a ser pensada. Política, ética e estética estão aqui intimamente implicadas. Tzvetan Todorov, em A beleza salvará o mundo (2011), traça, com clareza, o projeto romântico alemão de "Educação estética". Todorov assim explica a relação estrita entre artístico e político na filosofia de Schiller: "O belo conduzirá ao verdadeiro e ao bem, e o contato habitual com a arte terá ensinado aos homens a liberdade como igualdade, porque todos são iguais diante da beleza, e podem participar dela nas mesmas condições." (2011, p. 269). A beleza, assim, "não conhece privilégios sociais e nem de classe." (TODOROV, 2011, p. 269). Pensamento ingênuo, hoje o sabemos, mas imprescindível em

\footnotetext{
${ }^{2}$ Disponível em: < https://www.youtube.com/watch?v=5AcXIOUbsd8>. Acesso em: 10 jan. 2019.
} 
um período de crise moral e ética do indivíduo. Em uma sociedade na qual a instituição religiosa, cindida do Estado, está enfraquecida, a possibilidade de um indivíduo autônomo, que trabalha o seu "espírito" por meio de uma tessitura estética/ética é bem-vinda. Substituise, assim, o trabalho do clero por um trabalho de si consigo mesmo cujo objetivo é a produção de uma "vida nova". Para os românticos, a arte torna-se religião. Conforme Novalis: "Poeta e sacerdote eram um só, no começo, e só depois se diferenciaram. Mas o verdadeiro poeta permaneceu sempre sacerdote, assim como o verdadeiro sacerdote manteve-se poeta." (apud TODOROV, 2011, p. 270).

Ora, ao meu ver, a figura emblemática que vem ao encontro da "estética da existência" é a do dândi. Teorizado por Charles Baudelaire, o dândi é o indivíduo que revoluciona ao viver como obra de arte. O dândi é o homo aestheticus, o flâneur, aquele que Daniel Salvatore Schiffer (2012) denomina "super-dândi”. Dândi é Zaratustra, o mais humano, aquele que experimenta ser todos porque é todos. Dândi é o sujeito poroso constituído de vários eus, aquele que compõe dionisiacamente a cifra da sua vida, aquele que dedica a vida ao ócio e ao pensamento. Se dândi é flâneur, multidão, como compreendê-lo enquanto substância? Dândi é essencialmente ficção, ele dá forma vivendo no acaso. $\mathrm{O}$ alimento do dândi? $\mathrm{O}$ mesmo do flâneur, o devir. O passo dândi é lento, contemplativo, é um passo que resiste ao tempo da produção. Tal sujeito afirma com o corpo o seu estilo, a sua forma de vida, a sua singularidade. Ele se destaca do "rebanho" (NIETZSCHE, 2016) justamente por expressar quem é. O dândi revoluciona, ele quer ser um "vulcão" (ONFRAY 2017). Para Baudelaire (2010), os dândis "são todos dotados do mesmo caráter de oposição e de revolta; são todos representantes do que há de melhor no orgulho humano, dessa necessidade, bastante rara nos homens de hoje, de combater e de destruir a trivialidade.” (p. 65-66). Em As radicalidades existenciais (2017), Michel Onfray, na esteira de Baudelaire, assim explica: "O dândi é um cavaleiro do ser: recusa qualquer preocupação com o ter.” (2017, p. 24). E em seguida: "O dândi propõe construir-se como uma subjetividade irreplicável, numa época de homens unidimensionais.” (ONFRAY, 2017, p. 24). Baudelaire afirma que o dândi vive diante de um espelho. Acontece que não é devido, como muitos pensam erroneamente, a uma necessidade narcísica, a um egoísmo que o dândi assim o faz. Para Onfray, com quem acordo, viver diante de um espelho é um acessório, uma arte, um artifício que possibilita uma nova ética. Segundo Onfray, "[...] diante da superfície refletora, o dândi coloca-se como juiz e parte, criador e criatura, árbitro de seu bom gosto.” (2017, p. 25). Ora, não é esse o campo de batalha no qual o sujeito deve viver a relação agonística de si consigo próprio? Viver como obra de arte é dar vazão às possibilidades de existir. Essa é a ética dândi. 


\section{Oflâneur}

O conceito de "obra inoperante" é, nesse momento, fundamental. Em $O$ uso dos corpos, Agamben (2017) propõe uma nova forma de se pensar o sujeito. Ao criticar o sujeito substanciado, cindido da sua forma, cuja subjetividade, estacionada, está passiva ao sistema utilitário, o filósofo italiano opõe-se à tradição aristotélica que marca o sujeito por meio de uma ruptura com sua obra. Buscando desconstruir toda uma arquitetura discursiva que separa zoè, a "vida natural", de bios, ou "vida politicamente qualificada", e, portanto, toda uma estética do indivíduo - indivíduo que cristaliza um eu que ignora ser ficcional - portador de determinadas características, Agamben (2017) pensa um sujeito que acontece na práxis, um sujeito experimentador de si, artista de si. Para tanto, Agamben (2017) reflete acerca do que chama "forma-de-vida", uma vida que não se separa da sua forma. Ora, o artista apresenta esse estilo de vida. Na esteira de Karl Marx, o que está em discussão é uma "forma de inoperosidade" que resiste às "formas de produção" (MARX apud AGAMBEN, 2017), uma "forma-de-vida". A "forma-de-vida", que ocorre na imanência, é feita vivendo. Não há uma determinação prévia, um signo-Pai mantenedor de um idealismo sobre si mesmo. Para Agamben, "o que denominamos forma-de-vida corresponde a essa antologia do estilo; ela nomeia o modo como uma singularidade dá testemunho de si no ser, e o ser expressa a si em cada corpo" (2017, p. 261). Nessa concepção, sujeito é flâneur, artista de si mesmo. O que está em jogo é a desarticulação do modelo prévio de sujeito que o capitalismo nos propõe. Trata-se de profanar as velhas formas do eu, jogar - arte é um jogar com a vida -, por meio de novos usos possíveis do corpo, com as possibilidades de existir. Resiste-se, assim, à ideologia massificadora. Dândi, flâneur, conforme esse viés, é uma obra inoperante cujo estilo de vida, ao respeitar as próprias potencialidades, é um brincar com o instituído. Ao articular escapes possíveis - imanentes -, o dândi resiste ao discurso dominante.

Todorov (2011) lembra que Oscar Wilde pensava a estética enquanto "enriquecimento da ética". O artista completo, ou o dândi, para Wilde, é aquele que está aberto para todas as experiências. Dândi aqui é flâneur (BAUDELAIRE, 2010). Flâneur está aberto ao não eu. Flâneur, ao viver o instante, dá forma para a vida. Ora, permitir-se experienciar a si mesmo em um século tão sério como o XIX é um ato de resistência. Dândis, andróginos, excêntricos, malditos de olhar dançante, todos os que escapam ao comum rebanho portador de uma demasiadamente pesada estética burguesa. A arte de viver é a injeção vital necessária a uma sociedade marcada pelo signo da tristeza e da melancolia do crucificado. Criar é o antídoto 
para o torpor utilitarista. O artista de si é justamente o contraponto necessário ao status entediante da produção. É ato político o riso dândi, riso poeta do sujeito autêntico, aquele que, ao estetizar a si mesmo, é ele próprio.

O dândi é o sujeito que se permite experienciar a vida nos limites do possível. Ele não é um idealista, não sucumbe ao niilismo, o dândi resiste ao homem decadente por meio da arte de si, do trabalho estético de si. O corpo do dândi não pertence à Lei. Dândi é a coragem ética de afirmar quem se é por meio do trabalho ético de si. Dândi é o humano demasiado humano, aquele que se sabe homem e que se permite errar. É justamente porque se permite o erro que o dândi procura pelo aprimoramento. Para Onfray, o dandismo é, no século XIX - e até os nossos dias, ao meu ver -, uma "resistência à apatia de uma época de ferro e de aço, de dinheiro e de fumaça, de velocidade e de superficialidade.” (2017, p. 39). A subjetividade do dândi não é negociável justamente porque o dândi afirma aquele que é - todos. O dândi é uma obra em aberto; a sua singularidade, portanto, não pode ser compreendida por meio de um regramento. $\mathrm{O}$ estilo de vida do dândi é resistência à moralização, ao certo e ao errado categóricos. A arte de si pode ser aqui compreendida como uma fissura possível no instituído.

Viver como obra de arte é viver conforme uma ética aberta para as múltiplas formas de vida. Não pode aquele que vive com arte fechar-se em si mesmo, isso asfixiaria o seu florescer. Não há arte de si sem essa abertura para a vida. Viver como obra de arte, ser dândi nos dias de hoje é viver na franca aceitação da vida - amor fati. Desconstruir os paradigmas sexuais por meio de uma forma estética de colocar-se no mundo é uma resistência dândi. Viver como obra de arte é fazer do próprio corpo ruptura com o padrão. Trata-se de uma fissura necessária no tecido social para que o novo tenha vez. Dândi é a ética da inoperância, aquela que profana o que foi sacralizado (AGAMBEN, 2007). Hoje, muitas interferências no regramento moral estão ganhando visibilidade. A sexualidade está cada vez mais nuançada. $\mathrm{O}$ corpo, abrindo-se para a experimentação, está cada vez mais estético. A expressão da sexualidade, em conformidade com o desejo de cada um, é o que está em jogo. Abrir-se para as diversas formas de experimentação de si, é isso que está em questão para a forma de vida que não nega a existência do corpo. A arte de si é a fissura possível que resiste à velha moral que nunca sabe quando se torna obsoleta.

Pensar o sujeito e a sexualidade hoje é pensar a multiplicidade das formas de vida. O sujeito é feito na prática de si, por meio da experimentação de si enquanto indivíduo social. Em nossos dias, a crise da conhecida família tradicional nuclear soma-se ao enfraquecimento das regras de conduta com relação ao próprio desejo sexual. A desconstrução dos modelos sacrossantos de Homem e Mulher nos permite uma abertura significativa em relação à 
liberdade de cada sujeito sobre o próprio corpo. Resistir, por meio da arte de si, aos dispositivos culturais - forças institucionais que exigem do corpo o recalque, a moralização do prazer -, é um ato político fundamental em nossos dias.

\section{Conclusão}

Por fim, trata-se de um trabalho estético de si sobre si mesmo, uma terapêutica. Ora, aquele que vive como arte necessariamente deve estar inserido no tempo da flânerie, da contemplação. A obra inoperante não funciona fora do ritmo contemplativo. O que está em jogo na arte de si é o virtuosismo do sujeito que, por meio do passo lento, resiste ao tempo mecânico, utilitário. Ser si mesmo é respeitar um ritmo próprio, é afirmar um estilo. A arte de si ocorre na imanência. Trata-se de uma abertura para as formas de vida possíveis. O sujeito pratica a arte de si ao passear-se, ao experimentar-se. Corpos são campos de possibilidades. Onde está a determinação biológica? Não existe arte de si sem o trabalho ético de si consigo mesmo. Estética é ética. Artista é aquele que se experimenta no tempo da flânerie, aquele que vai ao encontro do não eu, aquele que não dita previamente o binarismo fascista que cinde masculino e feminino. Podemos pensar hoje o artista de si como aquele que foge às regras marcando um estilo e um discurso éticos. Vive como obra de arte aquele que, ao experienciar a si mesmo, sustenta a sua singularidade.

\section{Referências}

AGAMBEN, Giorgio. O uso dos corpos. 1. ed. São Paulo: Boitempo, 2017. 328 p.

AGAMBEN, Giorgio. Profanações. 1. ed. São Paulo: Boitempo, 2007. 96 p.

BAUDELAIRE, Charles. O pintor da vida moderna. Belo Horizonte: Autêntica, 2010. 152 p.

FOUCAULT, Michel. História da sexualidade: o uso dos prazeres. 2. vol. 3. ed. Rio de janeiro: Paz e Terra, 2017. 320 p.

NIETZSCHE, Friedrich. Genealogia da moral. 1. ed. Rio de Janeiro: BestBolso, 2016. 176 p.

ONFRAY, Michel. As radicalidades existenciais. São Paulo: Martins Fontes, 2017. 376 p.

SCHIFFER, Daniel Salvatore. Manifeste dandy. Paris: François Bourin Editeur, 2012. 216 p.

TODOROV, Tzvetan. A beleza salvará o mundo: Wilde, Rilke e Tsvetaeva: os aventureiros do absoluto. Rio de Janeiro: DIFEL, 2011. 352 p. 
RELACult - Revista Latino-Americana de Estudos em Cultura e Sociedade

Revista Latinoamericana de Estudios en Cultura y Sociedad | Latin American Journal of Studies in Culture and Society V. 05, ed. especial, abr., 2019, artigo $n^{\circ}$ 1191| claec.org/relacult | e-ISSN: 2525-7870

ULPIANO, Claudio. Sobre a estética da existência. Disponível em: < https://www.youtub e.co m/watch?v=5AcXIOUbsd8>. Acesso em: 10 jan. 2019. 